\title{
Congenital Garment Nevus (Giant Nevus)
}

\author{
Salvador Labrador*1, and Jose Manuel Llamazares Medrano ${ }^{2}$ \\ ${ }^{1}$ Family Medicine Physician, Centro de Salud de La Barrera, Spain \\ ${ }^{2}$ Family Medicine Physician, Centro de Salud de Berango, Spain \\ *Corresponding author: : Salvador Labrador, Health Center of Laredo, Cantabria, Spain.
}

To Cite This Article: Salvador Labrador.Congenital Garment Nevus (Giant Nevus) . Am J Biomed Sci \& Res. 2019 - 6(2). AJBSR.MS.ID.001007. DOI: 10.34297/AJBSR.2019.06.001007.

Received: 眥 November 04, 2019; Published: 制 November 12, 2019

\section{Opinion}

A 40 year old male from a suburban area of Spain, presented to our Clinic with respiratory symptoms. On examination we observed a dark hypermelanotic lesion on the dorsal and lumbar regions with areas of hypertrichosis on the lateral borders of this ovaloid shaped and dark skin patch. The affected area had a smooth and leathery appearance along with variegated lesions, light brown to black patches or plaques with smaller macules and papules (satellite nevi) in addition. (Figure 1) [1]. The patient admitted that he was born with this patch and had been diagnosed of dorsal Nevus, he also assured that the lesion had decreased in size over time [2]. This Clinical Image belongs to a Congenital Giant Nevus, (Figure 1) a type of hypermelanosis [3] _CongenitaI Nevi are often larger than Nevi that appear later in life. Garment Nevi also called Giant Nevi involve a very large body surface area-the entire back or a limband occur in 1/500,000 newborns. The frequency of Malignant transformation (Melanomas) in Congenital Nevi has been estimated to be between 2 and 20 per cent, although an incidence of 5 per cent was reported in a prospective series of 80 children. Rarely other neuroectodermal neoplasms develop in Congenital Nevi.

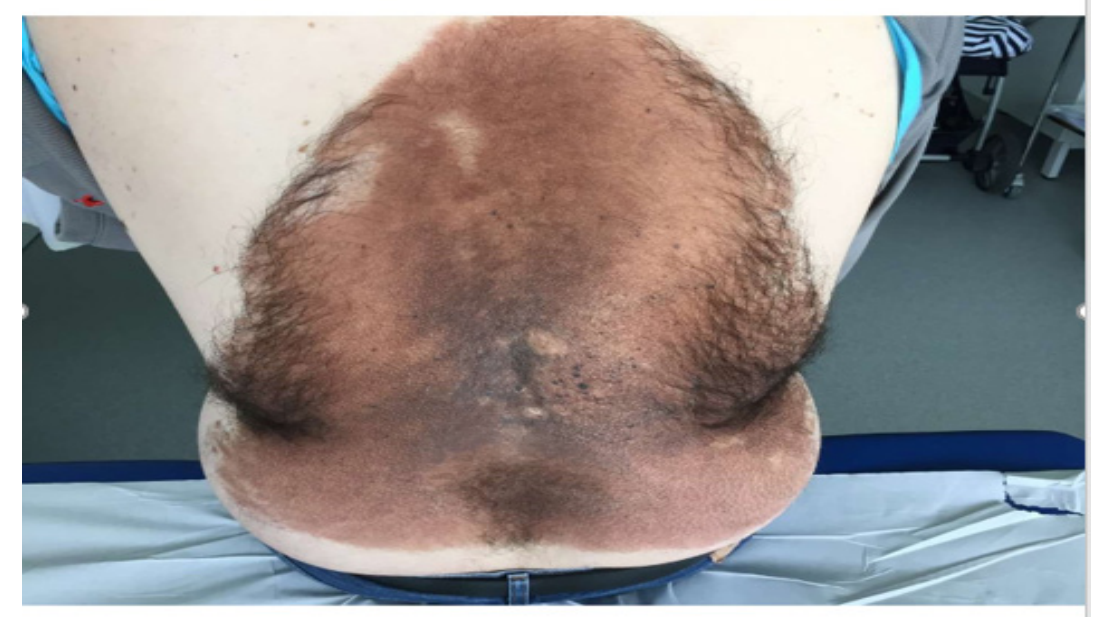

Figure 1

Congenital Giant nevi or bathing trunk nevus are usually present at birth Small Congenital Nevi are easily treated whereas large CN are problematic and disfiguring [3]. Giant "garment" nevi a rare kind of Nevus needs follow-ups and referral to Dermatologist whenever we meet skin alarm signs such as the acronym ABCDEF states. That is, Asymmetry of the lesion, Irregular Borders of the lesion, Changes in colour, Diameter increase of the lesion $(>6$ milimeters), Evolutionary changes or new symptoms and Finally odd or different shape. The presence of hair is presumptive that the lesion is intradermal [4] and the pigmentation or colour of the skin patch is seldom related with sun exposure and varies upon the observed area [5]. Although Congenital Giant Nevus is thought not to be a malignant condition, surveillance of these lesions are recommended. Differential Diagnosis should be made with 
Becker's Nevus and Dysplastic Nevi amongst other conditions. [5] The patient avoids exposure to sunlight when he goes to the beach in summer season.

\section{References}

1. Marcdante K, Kliegman RM (2015) Nelson Essentials of Pediatrics. Elsevier-Saunders ( $7^{\text {th }}$ Edition) 660-661.
2. Nasemann T (1983) Fundamentals of Dermatology Congenital Hairy Nevus. Springer-Verlag 254.

3. Sadlier MO, O’Regan GM (2015) N Eng J Med 372: 1249.

4. Spencer RP (1955) Malignant Melanoma N Eng JMed 253: 18-23.

5. (1999) Rassner's Dermatology Textbook and atlas. Melanocytic Nevus. Becker's Nevus. Harcourt-Brace ( (th $^{\text {th }}$ edition) 234 (Spanish Edition), Spain. 